\title{
Intra-raw material variability and use-wear accrual: A continuing exploration
}

\author{
Harry J. Lerner \\ Faculté des Lettres, Centre Interuniversitaire d'Études sur les Lettres, les Arts et les Traditions (CELAT), \\ Université Laval, Quebéc, Quebéc, Canada. Email: harry.lerner.1@ulaval.ca
}

\begin{abstract}
:
This paper presents the latest results of an ongoing research initiative into the role of lithic raw material variability in use-wear formation. The present study continues recent exploration of wear formation associated with working dry hide. The work presented here expands on a recently published study of two raw materials from the American Southwest (San Juan Fossiliferous Chert (SJF) and Yellow Silicified Wood (YSW)) by presenting the analysis of two additional materials (Morrison Undifferentiated Gray Chert (MUG) and Brushy Basin Silicified Siltstone (BB)) using the same quantitative measures from the previous study (area percent, density, average intensity). The methods used have broad geographic and temporal applicability, thus the potential for contributing to greater standardization in the quantification of archaeological use-wear.
\end{abstract}

Keywords: experimental; raw material variability; use-wear accrual; digital image analysis

\section{Introduction}

Great strides have been made in improving visualization of use-wear at high magnifications, but still lacking is a truly systematic way of documenting quantitatively the physical evidence of tool using behaviour. Any such quantification must be able to generate data that can be readily reproduced and easily compared between different subsistence activities, raw material types, and various lengths of use. The methods developed as part of the larger initiative, and used again here, are geared towards the realization of these admittedly lofty but eminently worthwhile goals.

While new interpretive ground needs to be broken, it is equally essential that intellectual continuity be maintained and promoted. The larger initiative is therefore designed to continue forging new methodological paths, while at the same time preserving and promoting the conceptual underpinnings that have guided the endeavor from the start. To these ends, this paper builds directly upon work previously carried out by the author (e.g. Lerner, 2007a, 2007b, 2009; Lerner et al, 2007; Lerner et al, 2010; Lerner in press), while at the same time introducing new data and new insights. Picking up where the last study left off, what follows is equally a further examination of the effects of intra-raw material variability on use-wear

Published by the School of History, Classics and Archaeology, University of Edinburgh ISSN: 2055-0472. URL: http://journals.ed.ac.uk/lithicstudies/

This work is licensed under a Creative Commons Attribution 2.5 UK: Scotland License. 
formation, and a continuing effort to re-test and re-evaluate the methods and variables employed to ensure maximum reliability of results.

In a recent paper by the author (Lerner, in press) an image analysis of experimentally generated wear on two raw materials (YSW and SJF) that were commonly used during the Late Archaic of northwestern New Mexico, corroborated earlier observations regarding differences in wear accrual on each of them (e.g. Lerner, 2007a, 2007b, 2009; Lerner et al 2010), and for the first time demonstrated how this process varied between multiple flake scrapers made from each. The present paper examines the intra-material variability of two additional types of lithic raw material (BB and MUG) that are found in the same geographic region and were used during the same time period, and compares current results with those of the previous study (Lerner, in press).

\section{Use-wear research at the crossroads}

After nearly fifty years of formal use-wear research, following the publication of Sergei Semenov's Prehistoric Technology (1964), this particular sub-discipline of archaeology has made many notable advances. It can even be argued that it has achieved a degree of methodological maturity. However, it currently stands at a sort of intellectual crossroads. While several analytical milestones have been achieved, one must ask 'have we maximized the interpretive potential of these traces?' Most use-wear analysts would say 'no, there is still more we can learn from them.' The question then becomes: 'How do we access this still elusory information?' One possible approach lies in methodological standardization.

Many different tacks have been taken when it comes to use-wear analysis and while each has its own merits few have achieved truly broad applicability. Historically, experimental usewear studies have often had as their focus the characterization and differentiation of wear attributes as a function of specific kinds of tool use (e.g. Tringham et al, 1974; Keeley, 1980; Vaughan, 1985; Kimball et al, 1995). While progress in this regard continues, lithic analysts can only advance so far until the very nature of use-wear formation is better understood.

Different theories have been put forward regarding how use-related wear actually forms. The first formal theory, the silica gel model, was introduced by Anderson (1980) and ascribed a primarily additive nature to use-wear formation. Subsequently, a more inclusive model, put forward by Mansur-Franchomme (1983a/b, 1986) and elaborated upon by Mansur (1997, 1999), emphasized the centrality of raw material variability in determining patterns of usewear accrual. The present study then serves to further improve our understanding of use-wear formation and demonstrate how a deeper appreciation of the underlying processes has the potential to significantly enhance our interpretations of these microscopic traces.

Perhaps one of the most-often cited yet least understood variables are the very materials from which stone tools are made. Any archaeologist that has dealt with lithic technology can tell you that no two kinds of stone are created equal. Despite this widely acknowledged reality, and the fact that use-wear analysis has been applied to tools made from a wide range of lithic raw materials, surprisingly little direct quantitative attention has been paid to how this variability influences the formation of use-related wear (e.g. Goodman, 1944; Greiser and Sheets, 1979; McDevitt, 1994; Stemp and Stemp, 2003). The larger initiative was therefore undertaken in an effort to address this issue and help build a more secure analytical foundation for the behavioural and cultural interpretation of archaeological use-wear evidence. The results of the initiative so far have shown that differences in use-wear accrual rates as a function of raw material variability can be reliably measured. This introduces the possibility of using this kind of data as a basis for assessing wear traces in new and exciting ways, such as evaluating the intensity of tool use in the archaeological record and how it may have changed over time and space. 
Each stage of the larger initiative is designed as a logical progression from previous installments. The first installments demonstrated quantitatively that different types of stone accrue wear at different rates. A more recent contribution (Lerner, in press) was based on the premise that the heterogeneous nature of most lithic materials suggests there may also be significant physical differences between different flakes of the same stone and therefore in how wear forms on each one. In the same vein the present study expands upon that paper by analyzing two further types of stone (BB and $\mathrm{MUG}$ ) and comparing the results from both investigations.

\section{Background of the present study}

The first installment of the larger initiative strived to gain a basic understanding of the physical differences between raw materials and how they influence the way they wear down during use (Lerner, 2007a, 2007b, 2009; Lerner et al 2007, Lerner et al 2010.) The four materials that the initiative has focused on (YSW, SJF, BB, and MUG) were chosen as a representative cross-section of grain size and surface texture variability. Late Archaic of northwestern New Mexico with its diverse record of lithic resource exploitation inspired the choice of raw materials studied and the initiative in general. Although beyond the purview of the current study given its primary goal of assessing in a preliminary manner the role of raw material variability in the use-wear accrual process, the petrographic characterization (cf. Mansur, 1999) of each raw material studied is essential for more fully understanding how wear forms on their respective surfaces and therefore how we interpret the resulting traces. This line of inquiry will thus form the basis for future installments of the larger initiative.

Experiments involving sequential stages of use were carried out to directly monitor wear formation through full image analysis of all tools after each stage of the experiment (Lerner 2007a, 2007b, 2009). Highly sophisticated image analysis techniques have often been used as diagnostic tools in other fields of research, including medicine, engineering, and the natural sciences (e.g. Alilou and Kovalev, 2013; Cootes, 2000; Graham, 2000; Gramfort et al, 2014; Moreaud et al, 2009; Parr and Polzleitner, 2001; Rottensteiner, 2001; Xu et al, 2011; Yoo and Metaxas, 2005).

Where it has seen relatively limited application is within the social sciences, particularly archaeology (e.g. Barceló Álvarez et al, 2008; Ibanez Estevez et al, 1999; González Urquijo and Ibáñez Estévez, 2003). Despite a long history of trying to quantify use-related wear, the field of use-wear analysis has only begun to realize the full potential of image-based techniques (e.g. Evans and Donahue, 2008; Evans and Macdonald, 2011; Dumont, 1982; Derndarsky and Ocklind, 2001; Grace, 1989, 1990; Grace, et al., 1985, 1987; Kimball, et al., 1995; Stemp and Stemp, 2001, 2003; Stemp et al, 2010).

Using Clemex Vision image analysis, differences in use-wear accrual rates proved not only measurable but also explicable, at least in part, in terms of each material's particular surface properties. Not surprisingly, raw materials with greater surface hardness tended to be more resistant to wear; however, the results also showed that surface roughness had an equal, if not greater, influence on rates of use-wear accrual (Lerner, 2007a, 2007b, 2009; Lerner et al, 2010). Of course, the ways in which these attributes influence use-wear formation depends on many factors, including the nature and degree of force being applied during use and the kind of use to which a given tool is being put (cf. Mansur, 1999).

Employing the same analytical technique, the present paper continues the intellectual journey of the initiative by expanding upon recent exploration into the intra-raw material variability of YSW and SJF (Lerner, in press) by investigating the other two raw materials, BB and MUG, and comparing the results from both studies. Improving and refining our understanding of intra-raw material variability is equally essential to understanding the 
overall process of wear accrual as clarifying how different raw materials wear down during use. And, understanding the overall process of wear accrual in all its dimensions is an absolute prerequisite for reliably interpreting any microscopic evidence of tool use.

\section{Methodology}

\subsection{Experimental design}

All lithic raw materials were collected in the field from secondary deposits throughout northwestern New Mexico. The nodules were taken to Dr. Michael Bisson of McGill University, a knapper with more than 30 years of experience, for production of the experimental tool assemblage. Dr. Bisson used hard-hammer percussion to detach flakes with at least one straight, acutely-angled edge suitable for scraping dry hide (Figures 1 and 2.) Each flake was bagged separately along with an index card bearing an illustration of the tool's outline indicating which edge was used. All relevant information pertaining to each tool and its use was recorded on its corresponding card.

Despite a growing body of literature, the very nature of archaeological use-wear formation remains poorly understood and the role of raw material variability in this process remains an even greater mystery. This, in part, may be due to some long-standing a priori assumptions about the distinctiveness of wear patterns associated with different kinds of activities, but the ever-present spectre of equifinality makes understanding the very nature of use-wear formation an inescapable necessity.

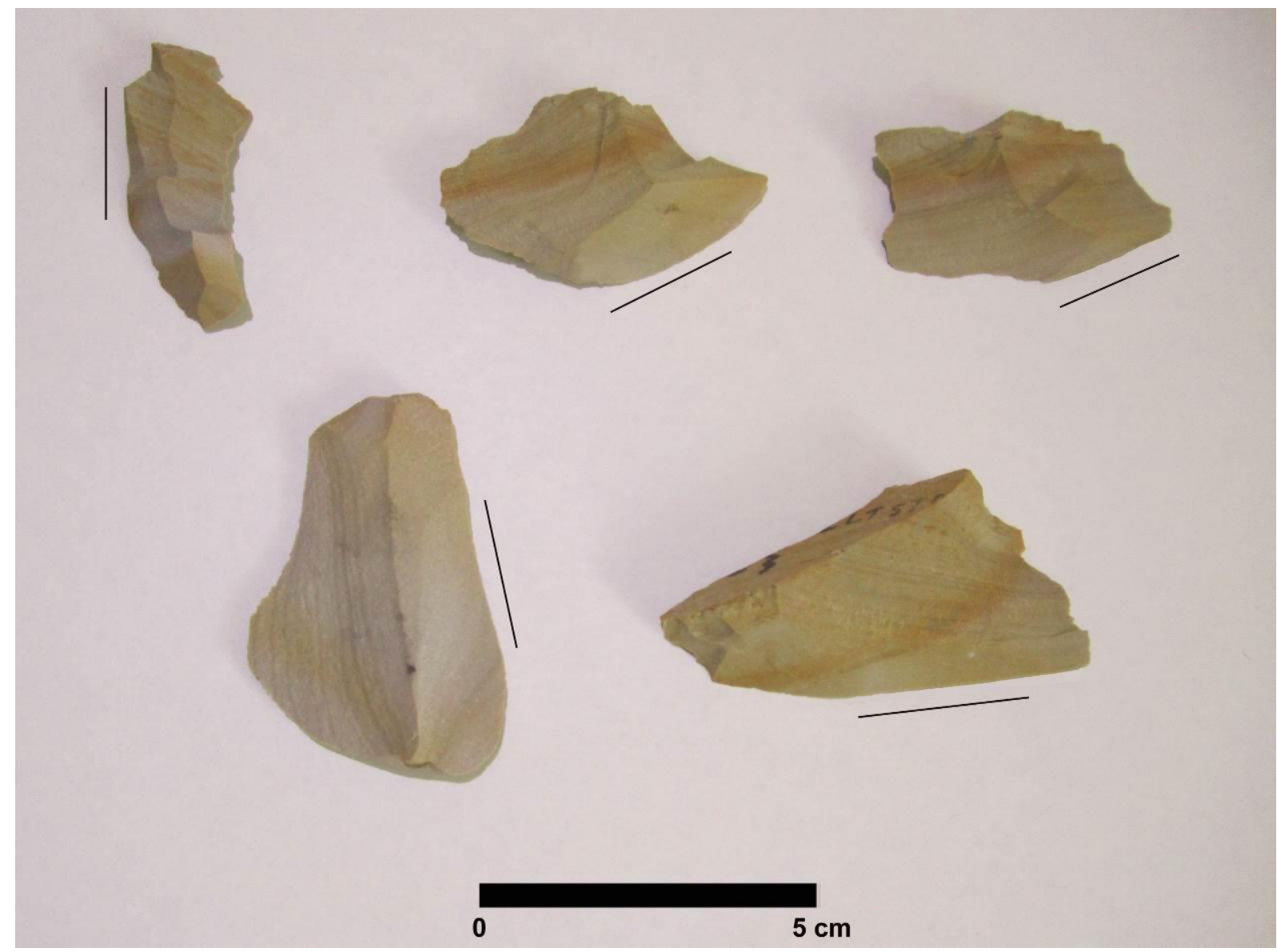

Figure 1: The experimental BB flake scrapers with utilized edges indicated. 


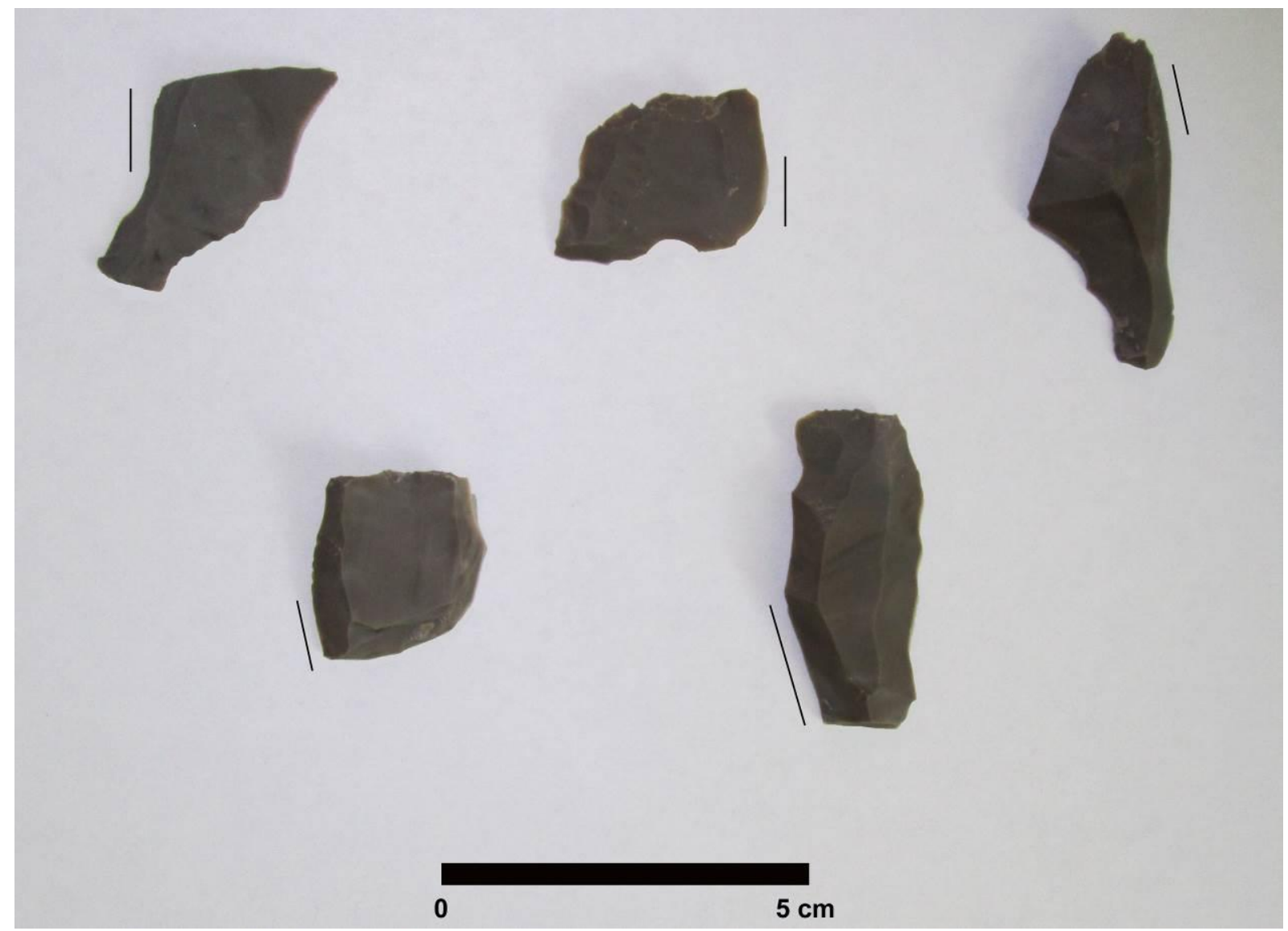

Figure 2: The experimental MUG flake scrapers with utilized edges indicated.

In an effort to address both of these issues a sequential experimental design was used. Each flake scraper was used for 10 minutes then subjected to full cleaning and analysis. The cleaning protocols consisted of first washing each tool in warm water with mild detergent to remove all visible residues and debris. Each was then soaked for $30 \mathrm{~min}$ in a sonic bath of $30 \% \mathrm{NaOH}$ solution using a Brandon 1510 Sonic Cleaner. Finally, each tool was rinsed with distilled water to remove any contamination associated with their handling. A wash with $10 \%$ $\mathrm{HCl}$ solution was considered, but since in prehistory adhering residues likely acted as tertiary abrasive agents the decision was made to omit this step to maximize the relevancy of results for future comparison to archaeological data.

The tools were then used for another 20 minutes, subjected to another round of cleaning and analysis, used for a further 30 minutes then cleaned and analyzed one again. This process resulted in each tool being used for a total of 60 minutes. All flake scrapers were used in exactly the same manner throughout to ensure consistency of activity performance. Each tool was held at a 45 degree angle to the hide and used with consistent stroke lengths of 6 to 8 inches and a constant stroke rate of one per second. All use-motion was uni-directional with the tool being placed initially away from and then dragged towards the experimenter.

A group of nine students from Université Laval helped carry out the experiments. The lack of occupational specialization during the Late Archaic of northwestern New Mexico, the multi-stage nature of the experimental program, and the large number of replicated tools all lead to the decision to involve several experimenters in the study. Detailed instructions were given to all participants prior to starting the experiments and activity performance was closely monitored by the author throughout the experimental program.

The ungulate hide was secured to plywood to ensure it would remain immobile while being worked (Figure 3). The experiment was not designed to replicate prehistoric hide 
working in detail as the priority was to further clarify the nature of wear accrual as a function of raw material variability rather than fully prepare a hide. Once the wear accrual process is more clearly understood then experiments designed to emulate more precisely the prehistoric preparation of animal hides will be undertaken. The experimental flake scrapers were made as unretouched hand-held tools, much as they were during the Late Archaic of northwestern New Mexico.

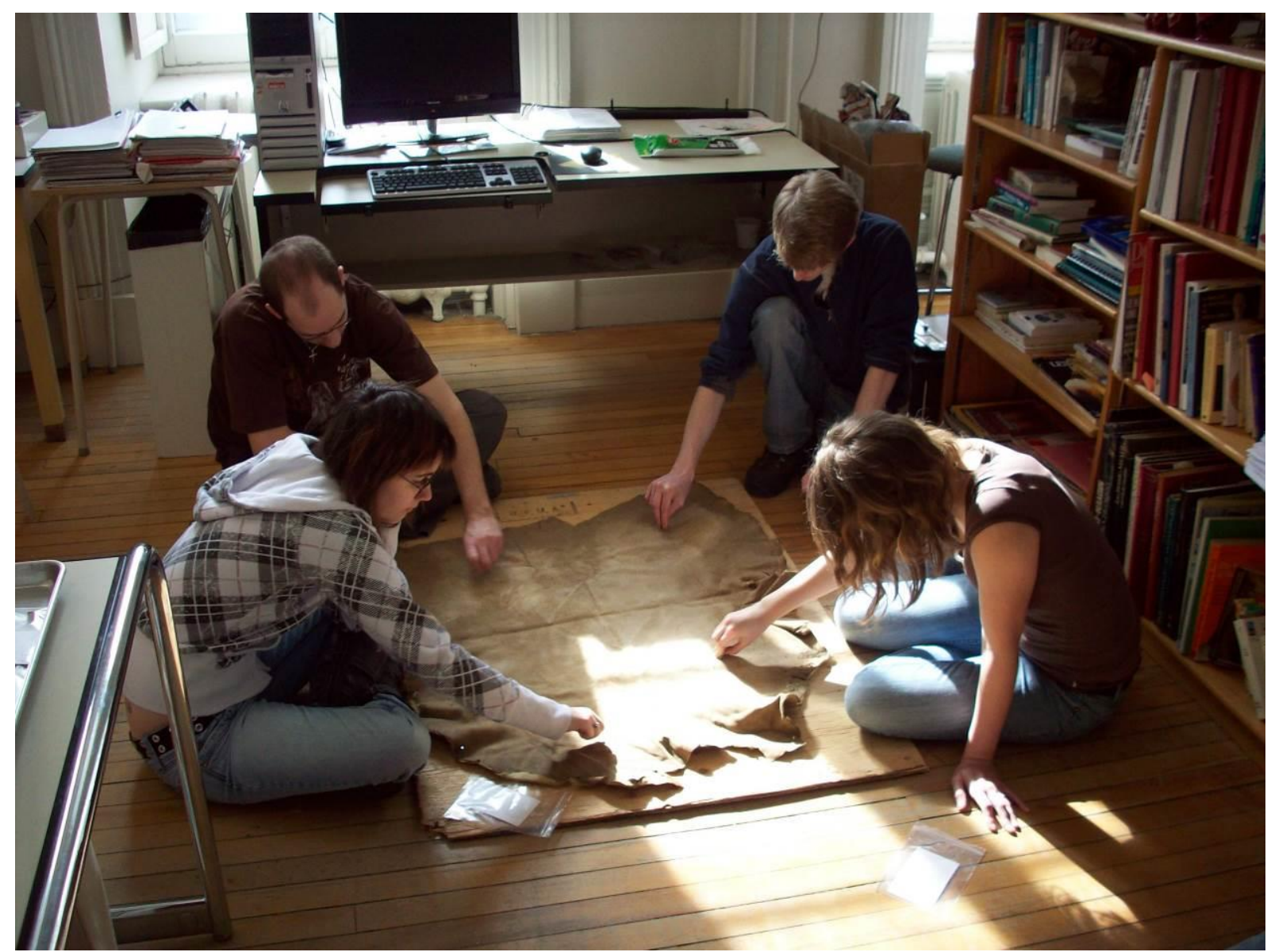

Figure 3: Experimenters scraping the dry ungulate hide.

The analytical technology used here is the same as in previous installments of the larger initiative (e.g. Lerner, 2007a, 2007b, 2009), the sole exception being a switch from scanning electron microscopy (SEM) to optical light microscopy (OLM). This change was made to determine if the methods being developed are equally effective when used with a less expensive and more readily available form of analytical microscopy.

After each stage of the experiment each tool was examined using a Zeiss Axioscop 2 Mat upright metallographic incident light microscope. All examinations and microphotography were conducted at 100x magnification to provide a wider field of view and therefore a greater amount of surface area per image to sample with the Clemex processing frame in an effort to maximize both data collection and the reliability of results. A single level of magnification was also used to facilitate detailed and direct comparisons between all tools and all stages of the experiment. Again, the present aim is focused on identifying any basic patterns of usewear accrual directly attributable to raw material variability. Higher magnifications will be used in future installments of the larger initiative to both further test the validity of current findings and to expand our understanding of the myriad complexities of the use-wear formation process. 
All photomicrographs were taken with a Nikon E4500 CoolPix camera using an f-stop of $\mathrm{f} / 3.7$, an exposure time of $1 / 8$ of a second, an ISO speed of ISO-112, a focal length of $8 \mathrm{~mm}$, and a maximum aperture of 2.8. The Zeiss's light source was oriented perpendicularly (at 90 degrees) to each tool surface. Brightness was controlled using an integrated dial on the Zeiss that adjusts beam intensity from 10 to 100 Watts. A moderate setting of 60 Watts was used to examine and photograph all experimental tools. All of the camera and light source settings were kept constant to avoid any variability that changing them might introduce.

Once the examination of each scraper was complete multiple photomicrographs were taken of each tool surface to fully document all visible traces of use. The number of images recorded for each tool reflects the extent of wear it exhibited; the more extensive the wear the greater the number of images. These images were then imported into the Clemex Vision image analysis software package for quantitative analysis.

\subsection{The variables and their measurement}

The Clemex processing frame (Figure 4) was again used to record the same variables as in the previous study (Lerner, in press). Among these variables, the first, area percent, is simply the percentage of the total area within the processing frame that exhibits physical evidence of wear. The second, density, is the number of objects within the processing frame that depict use-related wear divided by the total area of the processing frame. An object in any image, as defined by Clemex, is either an isolated pixel if it is not in direct contact with any other pixel within the same bitplane or as being composed of two or more pixels within the same bitplane if these pixels are in direct horizontal, vertical or diagonal contact with each other, following the basic principles of stereology.

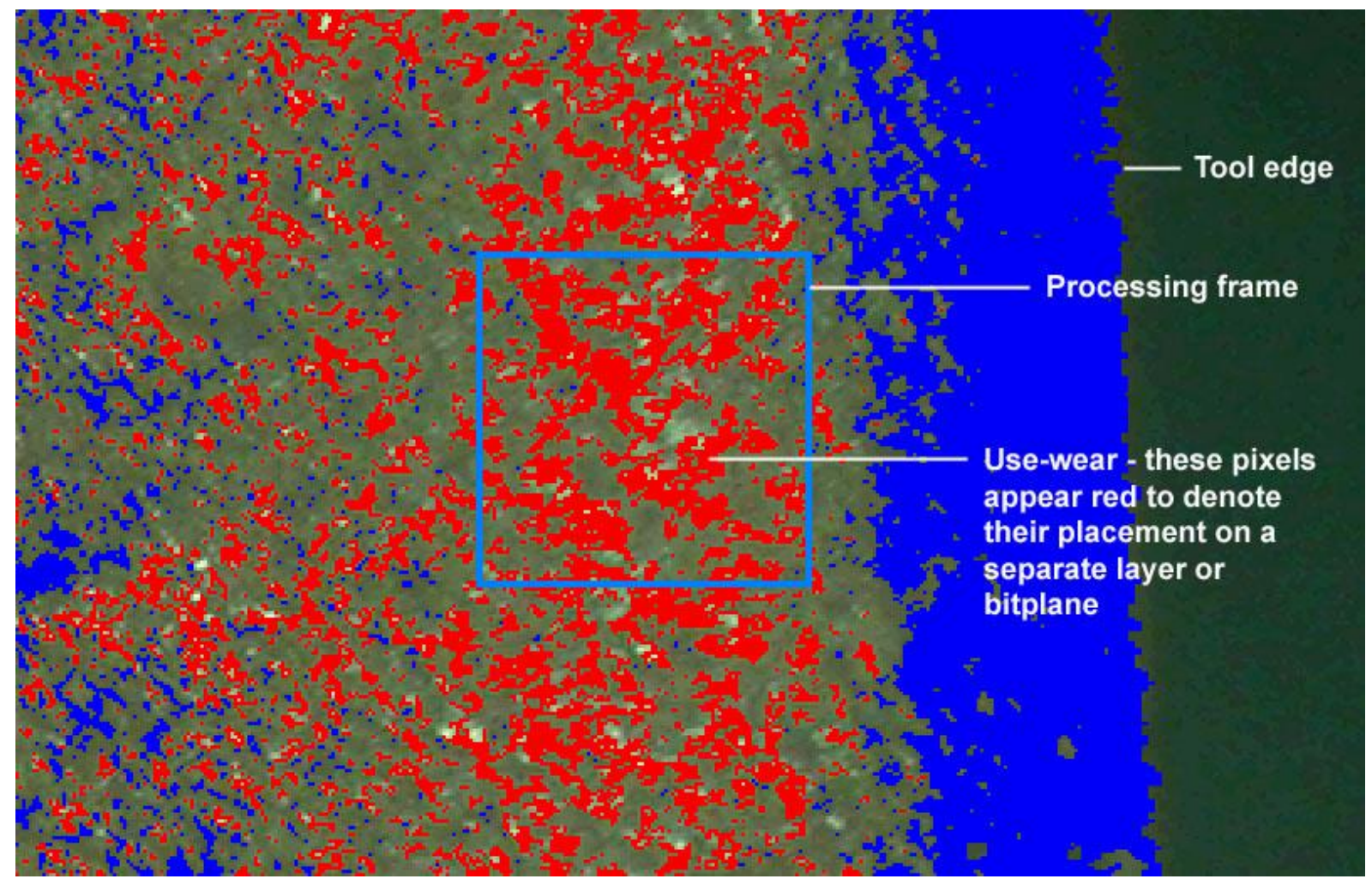

Figure 4: The Clemex processing frame.

Although the recorded densities are very low, this should not be taken as an indication of limited wear. As wear develops the more area it covers, and the more inter-connected the 
pixels become that depict such wear (Figure 5). Density values are therefore numerically low due to the typically small number of discrete objects recognized by Clemex as part of how it calculates this variable. Thus, their significance lies in how they change from one stage of the experiment to the next and in differences between individual tools rather than in their absolute values.

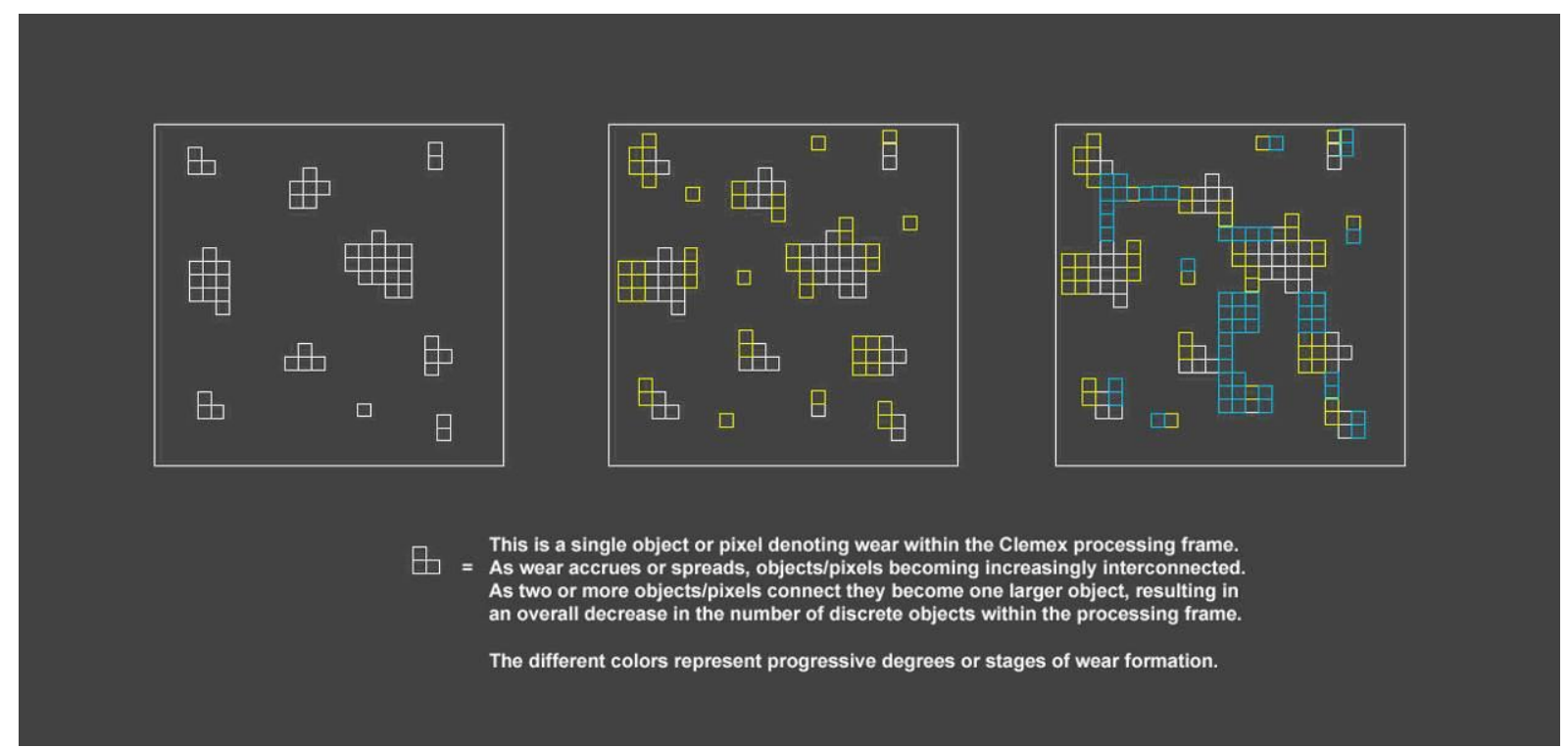

Figure 5: An illustration of how Clemex records the density of objects within the processing frame.

Finally, average intensity, is the sum of individual gray values (1 to 256 in a grayscale image) for all pixels associated with wear divided by the total number of pixels within the processing frame. Average intensity is measured on a scale from 0 to 100 , where 0 indicates the pixels in question are pure black and 100 indicates the pixels are pure white. All shades of gray, hence all levels of light reflectivity, fall somewhere in between.

Visible wear was digitally highlighted relative to the surrounding tool surface through the use of histogram-based thresholding. Thresholding or image segmentation was used to differentiate pixels associated with use-related wear from pixels that denote unworn portions of a tool's surface. The threshold histograms in Clemex are based on individual pixel gray values that range from 0 (black) to 255 (white) and together comprise the full spectrum of a standard 256 grayscale image. Each bar in the histogram represents a range of four consecutive pixel gray values (e.g. 0-3, 4-7, etc.).

As a result, the bars representing pixel gray values closer to 255 (shades approaching white) denoting points exhibiting greater light reflectivity or wear can be easily delineated from the rest of the histogram via manually adjustable linear (intensity) and radial (shade) scales within the histogram dialog box (Figure 6). Thresholding thus offers a less subjective way of enhancing visible wear in original photomicrographs while retaining all the relevant textural detail of each surface. This fosters more consistent and reliable measurement of attributes and thus greater comparability of results between images. The highlighted pixels were then assigned to their own layer or bitplane within the original image, in this case denoted on screen by the color red.

The processing frame was used to collect data from multiple surface samples of highlighted wear along the entire length of each utilized edge as a basis for further quantitative analysis (Figure 7). The user can adjust manually the dimensions of the processing frame and therefore the size of each surface sample. A processing frame measuring 100 x 100 pixels (where 1 pixel measures $1 \times 1 \square \mathrm{m}$ ) was used to record all surface 
samples on all tools. Three separate measurements were taken from each surface sample: area percent, density and average intensity. A minimum of five surface samples, but typically twice as many or more, were taken from each tool to generate representative mean values for each variable. It was only on tools that exhibited very slow rates of wear accrual where as few as five surface samples were taken.

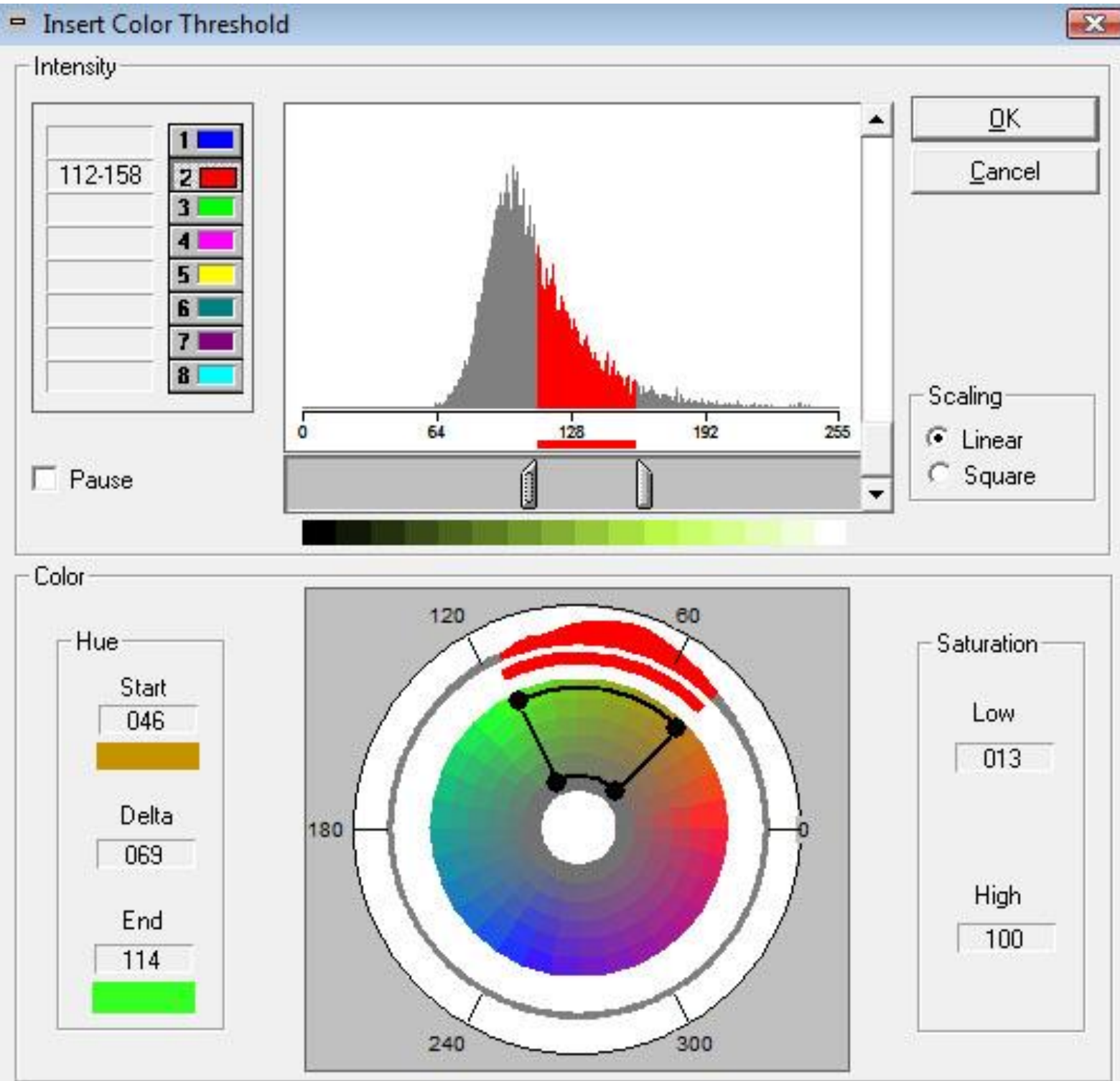

Figure 6: The Thresholding dialog box within Clemex.

Based on the resulting data a series of scatter plots were generated to serve three purposes. First, to re-assess the inter-raw material patterning observed during earlier installments of the larger initiative. Second, to identify any trends in use-wear accrual associated with intra-raw material variability specific to BB and MUG. And, finally, to see if any new light could be shed on the overall role of intra-raw material variability in use-wear accrual through comparisons between the data generated in this study and those from the last installment. 


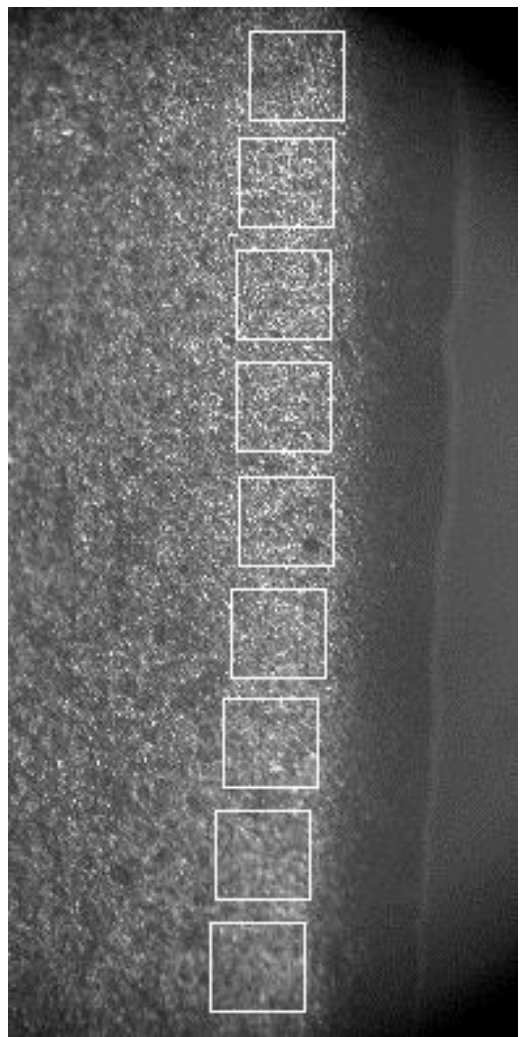

Figure 7: Processing frame surface sampling strategy.

\section{Results}

The most recent installment of the larger initiative (Lerner, in press) not only confirmed the general patterns of inter-raw material wear accrual documented previously for YSW and SJF (e.g. Lerner, 2007a, 2007b, 2009, 2010), but also revealed some rather telling trends in terms of intra-raw material patterns of wear formation. It showed that the YSW flake scrapers tended to be more variable in terms of how wear accrued on their surfaces, while the SJF flake scrapers exhibited more consistent patterns of wear development (Lerner, in press).

The present experiment with BB and MUG provided some interesting insights into the behaviour of these particular materials and these findings helped to shed some further light onto the broader relationship between intra-raw material variability and use-wear accrual (see Figure 8). As in the last study all variables are considered in terms of both range and percent difference between minimum and maximum mean values, the last being simply the range between the minimum and maximum values divided by the minimum value. As will be demonstrated below, it is as much, if not more so, the change in variable values from one stage of the experiment to the next as the values themselves that offer the greatest insights into intra-raw material patterns of wear accrual.

Summary data are provided in Tables 1 and 2. The mean area percent of wear for BB after 10 minutes of use ranged from a minimum of $3.47 \%$ to a maximum of $20.09 \%$, from $2.03 \%$ to $8.49 \%$ after 30 minutes, and from $3.59 \%$ to $8.12 \%$ after 60 minutes of use. The anomalously high maximum mean value after 10 minutes of use is associated with BB Tool \#1 and may be attributable to a particularly low surface hardness and therefore more rapid rate of wear accrual for this particular scraper (cf. Lerner et al, 2007). Apart from this, the values are generally consistent and exhibit a progressive decrease in percent difference through all three stages of the experiment from $479 \%$ through $318.2 \%$ to finally $126.2 \%$. 

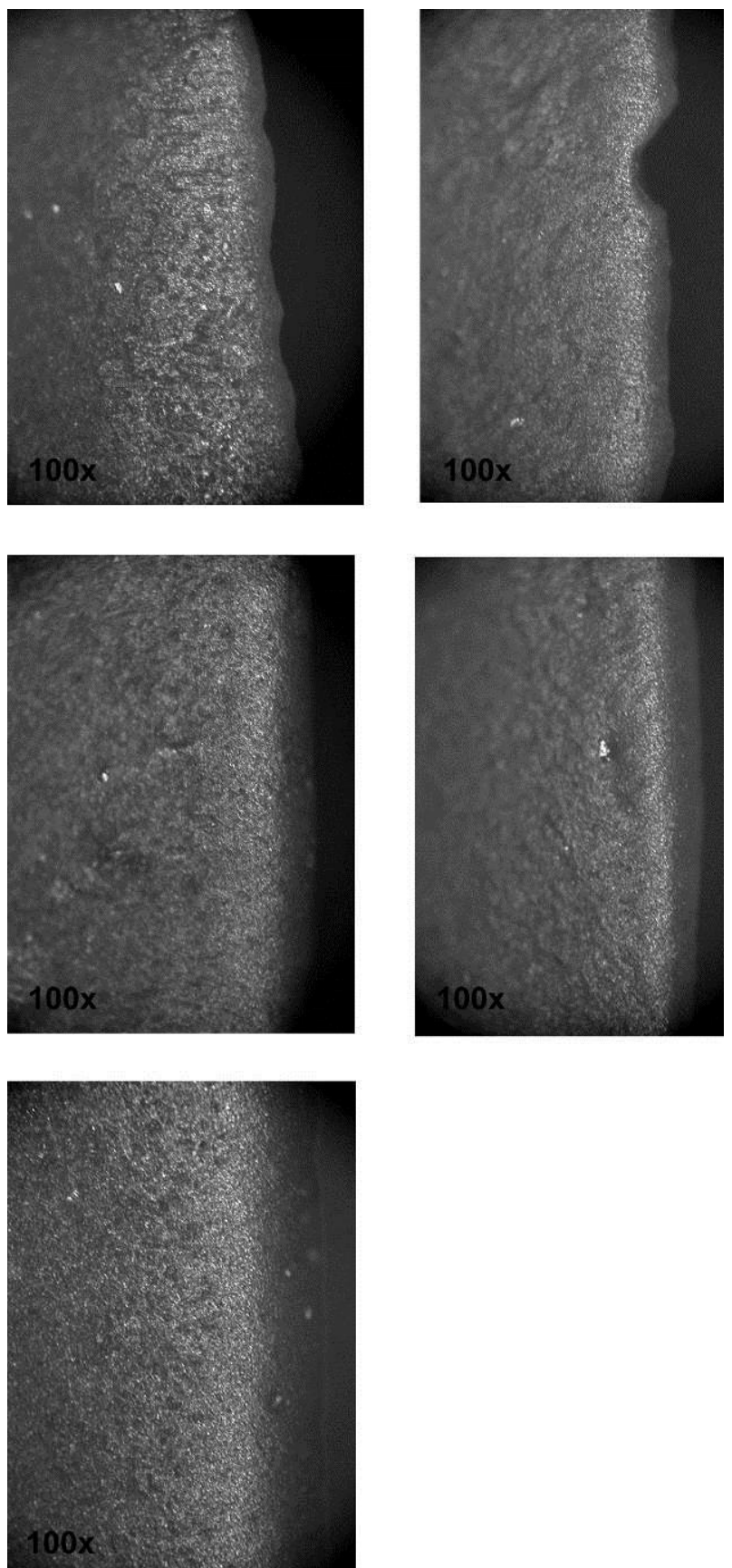

Figure 8: The experimental MUG tools after scraping dry ungulate hide for 30 minutes.

The mean density of wear for BB ranged from a minimum of 0.0012 to a maximum of 0.0069 after 10 minutes, from 0.0028 to 0.0179 after 30 minutes, and from 0.0058 to 0.0111 after 60 minutes of use. The percent difference for mean density was $475 \%$ after 10 minutes, increasing to $539.3 \%$ after 30 minutes, and dropping significantly to $91.4 \%$ after 60 minutes of use. The mean average intensity for BB ranged from a minimum of 43.87 to a maximum of 57.89 after 10 minutes, from 38.08 to 43.27 after 30 minutes, and from 40.70 to 44.93 after 60 minutes of use. The percent difference for mean average intensity also decreased progressively from $32 \%$ after 10 minutes to $13.6 \%$ after 30 minutes and finally to $10.4 \%$ after 60 minutes of use.

Although BB exhibited a certain amount of variability in how wear accrued on each scraper, there was some consistency in the results, particularly a tendency towards decreasing percent difference values as the experiment progressed. The MUG flake scrapers presented 
somewhat different results. The mean area percent for the MUG tools ranged from a minimum of $6.28 \%$ to a maximum of $31.60 \%$ after 10 minutes, from $19.22 \%$ to $32.43 \%$ after 30 minutes, and from $24.90 \%$ to $51.74 \%$ after 60 minutes of use. The percent difference for mean area percent was $403.2 \%$ after 10 minutes then dropped to $68.7 \%$ after 30 minutes and increased again to $107.8 \%$ after 60 minutes of use. While the mean percent area values show a clear increase in wear accrual throughout the experiment, the percent differences suggest a considerable amount of variability in the rates at which the wear accrued.

Table 1: Summary data for the experimental BB flake scrapers.

\begin{tabular}{|c|c|c|c|c|c|}
\hline \multirow[b]{2}{*}{ Area Percent (\%) } & \multicolumn{5}{|l|}{ BB } \\
\hline & Min to Max & Mean & Std Dev & Range & $\%$ Difference \\
\hline $10 \min$ & 3.47 to 20.09 & 7.22 & 9.02 & 16.62 & 479 \\
\hline $30 \mathrm{~min}$ & 2.03 to 8.49 & 3.89 & 4.19 & 6.46 & 318.2 \\
\hline $60 \mathrm{~min}$ & 3.59 to 8.12 & 6.89 & 5.97 & 4.53 & 126.2 \\
\hline \multicolumn{6}{|c|}{ Density (No. of objects/Total Area) } \\
\hline $10 \mathrm{~min}$ & 0.0012 to 0.0069 & 0.0033 & 0.0026 & 0.0057 & 475 \\
\hline $30 \mathrm{~min}$ & 0.0028 to 0.0179 & 0.0059 & 0.0068 & 0.0151 & 539.3 \\
\hline $60 \mathrm{~min}$ & 0.0058 to 0.0111 & 0.0082 & 0.0043 & 0.0053 & 91.4 \\
\hline \multicolumn{6}{|c|}{$\begin{array}{l}\text { Average Intensity ( } \Sigma \text { pixel grey } \\
\text { values/Total no. of pixels) }\end{array}$} \\
\hline $10 \mathrm{~min}$ & 43.87 to 57.89 & 51.01 & 5.61 & 14.02 & 32 \\
\hline $30 \mathrm{~min}$ & 38.08 to 43.27 & 41.57 & 2.45 & 5.19 & 13.6 \\
\hline $60 \mathrm{~min}$ & 40.70 to 44.93 & 42.74 & 1.68 & 4.23 & 10.4 \\
\hline
\end{tabular}

Table 2: Summary data for the experimental MUG scrapers.

\begin{tabular}{|c|c|c|c|c|c|}
\hline \multirow[b]{2}{*}{ Area Percent (\%) } & \multicolumn{5}{|l|}{ MUG } \\
\hline & Min to Max & Mean & Std Dev & Range & $\%$ Difference \\
\hline $10 \mathrm{~min}$ & 6.28 to 31.60 & 21.00 & 13.74 & 25.32 & 403.2 \\
\hline $30 \mathrm{~min}$ & 19.22 to 32.43 & 26.65 & 9.9 & 13.21 & 68.7 \\
\hline $60 \mathrm{~min}$ & 24.90 to 51.74 & 35.18 & 12.91 & 26.84 & 107.8 \\
\hline \multicolumn{6}{|c|}{ Density (No. of objects/Total Area) } \\
\hline $10 \mathrm{~min}$ & 0.0018 to 0.0111 & 0.0076 & 0.0043 & 0.0093 & 516.7 \\
\hline $30 \mathrm{~min}$ & 0.0096 to 0.0164 & 0.0122 & 0.0042 & 0.0068 & 70.8 \\
\hline $60 \mathrm{~min}$ & 0.0045 to 0.0158 & 0.0116 & 0.0053 & 0.0113 & 251.1 \\
\hline \multicolumn{6}{|c|}{$\begin{array}{l}\text { Average Intensity ( } \Sigma \text { pixel grey } \\
\text { values/Total no. of pixels) }\end{array}$} \\
\hline $10 \mathrm{~min}$ & 51.26 to 57.11 & 54.99 & 4.05 & 5.85 & 11.4 \\
\hline $30 \mathrm{~min}$ & 43.97 to 51.48 & 46.43 & 2.40 & 7.51 & 17.1 \\
\hline $60 \mathrm{~min}$ & 42.93 to 46.91 & 44.24 & 2.38 & 3.98 & 9.3 \\
\hline
\end{tabular}

The mean density for MUG ranged from a minimum of 0.0018 to a maximum of 0.0111 after 10 minutes, from 0.0096 to 0.0164 after 30 minutes, and from 0.0045 to 0.0158 after 60 minutes of use. The percent difference was $516.7 \%$ after 10 minutes, dropping significantly to $70.8 \%$ after 30 minutes, and rebounding to $251.1 \%$ after 60 minutes of use. The mean average intensity for the MUG flake scrapers ranged from a minimum of 51.26 to a maximum of 57.11 after 10 minutes, from 43.97 to 51.48 after 30 minutes and finally from 42.93 to 46.91 after 60 minutes of experimental use. The percent difference was $11.4 \%$ after 10 minutes, increased to $17.1 \%$ after 30 minutes, and dropped to $9.3 \%$ after 60 minutes of use. 
The mean average intensity for the BB flake scrapers ranged from 43.87 to 57.89 after 10 minutes, from 38.08 to 43.27 after 30 minutes, and from 40.70 to 44.93 after 60 minutes of use. The percent difference was $32.0 \%$ after 10 minutes, $13.6 \%$ after 30 minutes, and $10.4 \%$ after 60 minutes. The mean average intensity for the MUG scrapers ranged from 51.26 to 57.11 after 10 minutes, from 43.97 to 51.48 after 30 minutes, and from 42.93 to 46.91 after 60 minutes of use. The percent difference was $11.4 \%$ after 10 minutes, $17.1 \%$ after 30 minutes, and $9.3 \%$ after 60 minutes of use. For both materials there was a net decrease in mean average intensity over the course of the experiment, yet there are noticeable differences in the way those decreases were achieved.

These findings may shed some further light on the respective roles of surface hardness and surface roughness in the wear accrual process. The insights gleaned here and their potential relationship to those gained from the previous study (Lerner, in press) will both be examined in greater detail below.

\section{Discussion}

Lithic use-wear analysts have spent a great deal of time trying to develop a reliable means of identifying different forms of use-related wear to aid in their reconstructions of prehistoric human adaptations. The reliability of such identifications, however, is directly dependent on a clear and thorough understanding of how wear forms. The rates of wear accrual as a function of raw material type recorded during earlier phases of the initiative were confirmed by the results presented above. This demonstrates a general consistency in the way each stone studied responds to working dry hide. However, this analysis also showed that within these broader patterns there exists some degree of variability in rates of wear accrual between multiple samples of each raw material.

In the previous installment (Lerner, in press) the rate of use-wear accrual was examined on flake scrapers made from a silicified wood (YSW) and a fossiliferous chert (SJF). These two materials represent two ends of a spectrum of raw material variability based on individual grain size and resulting surface roughness or texture. YSW is cryptocrystalline and thus typically exhibits a very even or smooth microtopography. SJF, on the other hand, is characterized by a larger average grain size thus usually exhibits a great deal of surface irregularity, including multiple microfossil inclusions. The present paper offers the analysis of two additional materials (BB and MUG) that occupy intermediate locations within this same spectrum of lithic raw material variability. As such, in addition to considering the possible implications of current results, comparisons between present findings and those of the previous installment offer a unique opportunity to shed some additional light on the relationship between intra-raw material variability and patterns of use-wear accrual.

As previously demonstrated, the rate at which wear forms on a given tool surface is a function of both its surface hardness and surface roughness (Lerner, 2007a, 2007b, 2009, 2014; Lerner et al 2007; Lerner et al 2010). These results were corroborated by the data from the most recently published study (Lerner, in press) that indicate YSW flake scrapers not only accrued wear more rapidly but also exhibited greater variability in their rates of wear accrual than did SJF flake scrapers. A major factor in its faster rate of wear accrual, YSW's lower surface roughness may allow for greater flexibility in how wear spreads across each tool surface.

With SJF, its more irregular microtopography may serve to micro-morphologically restrict the progression of wear over its surface resulting in more consistent, if slower, patterns of wear accrual. Unlike YSW or SJF, BB is characterized by lower surface hardness but higher surface roughness values (Lerner et al 2007). MUG, on the other hand, has a smaller average grain size and a more even microtopography than either BB or SJF, and has 
an intermediate surface hardness relative to harder YSW and SJF and softer BB (Lerner et al 2007). Again, it is important to note that in order to more fully understand how the various surface properties of a given raw material interact to influence the rate of use-wear accrual, full petrographic analysis of each material is essential and, as such, will form the basis for future installments of the larger initiative. Considering the initial purpose of the initiative is to identify any larger-scale patterning in use-wear formation associated directly with raw material variability, the admittedly qualitative inferences described above can serve as a preliminary explanatory framework that will be used to guide the direction of future research.

Further assessment of present data involved generating a series of area percent versus density scatter plots and corresponding $\mathrm{R}^{2}$ values (Figures $9-14$ ). The $\mathrm{R}^{2}$ values for $\mathrm{BB}$ were consistently fairly high through all three stages of the experiment (after 10 mins $R^{2}=0.5650$, after 30 mins $R^{2}=0.5628$, and after 60 mins $R^{2}=0.3872$ ) and higher than those for MUG after the first two stages indicating a strong positive correlation between these two variables for BB and therefore a more consistent pattern of wear accrual across all scrapers made from this material. The $\mathrm{R}^{2}$ values for MUG tended to be lower than those for BB except after the final stage of the experiment (after 10 mins $R^{2}=0.4606$, after 30 mins $R^{2}=0.0968$, and after 60 mins $R^{2}=0.8533$ ), demonstrating greater variability in patterns of wear accrual.

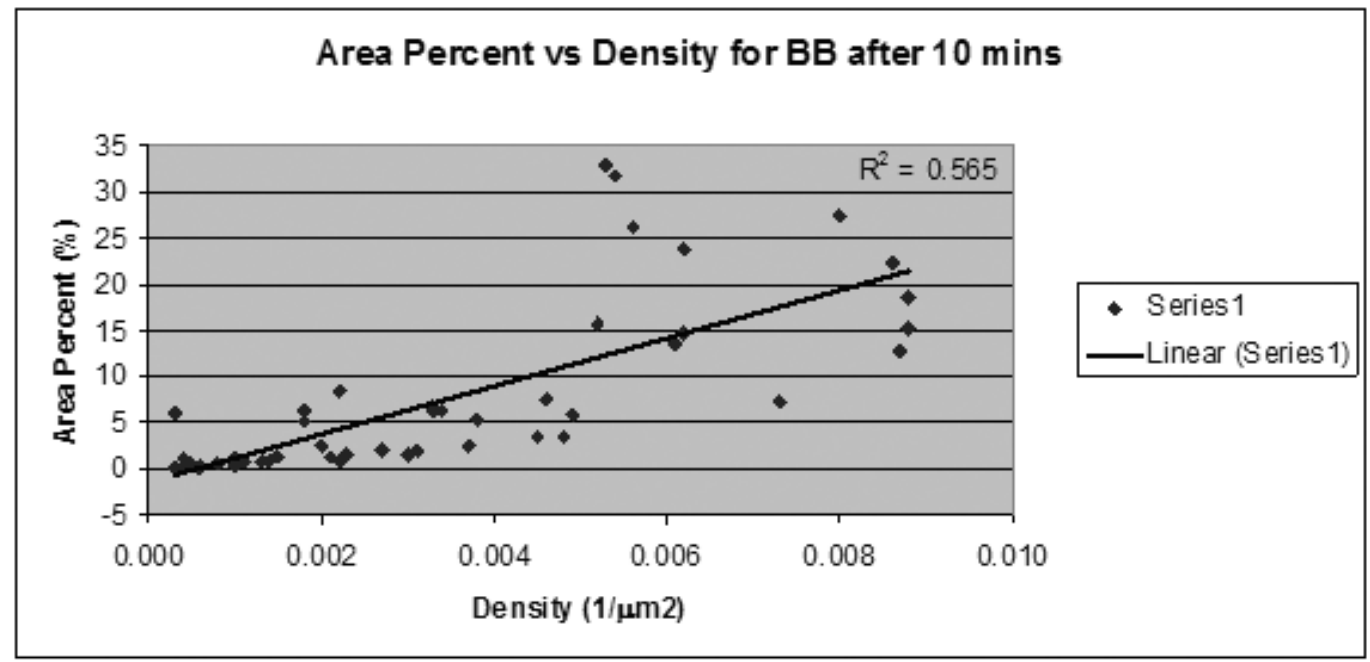

Figure 9: Area Percent vs. Density of wear for BB after 10 minutes.

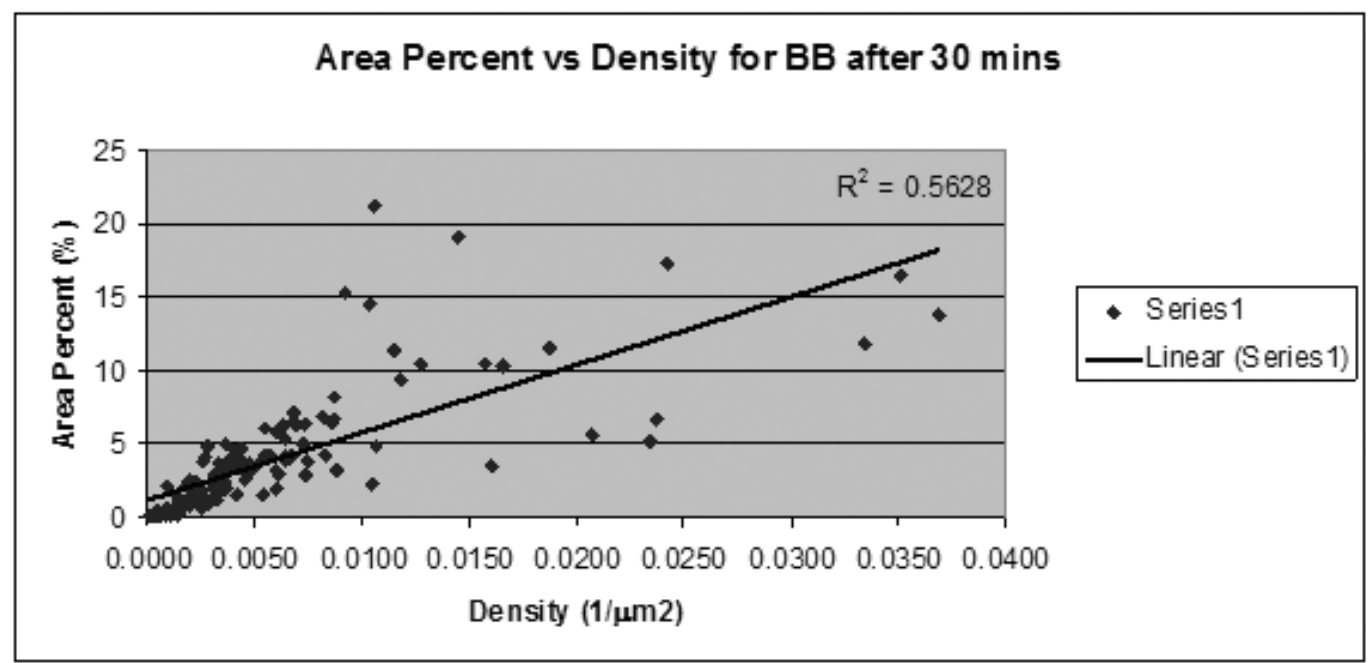

Figure 10: Area Percent vs. Density of wear for BB after 30 minutes. 


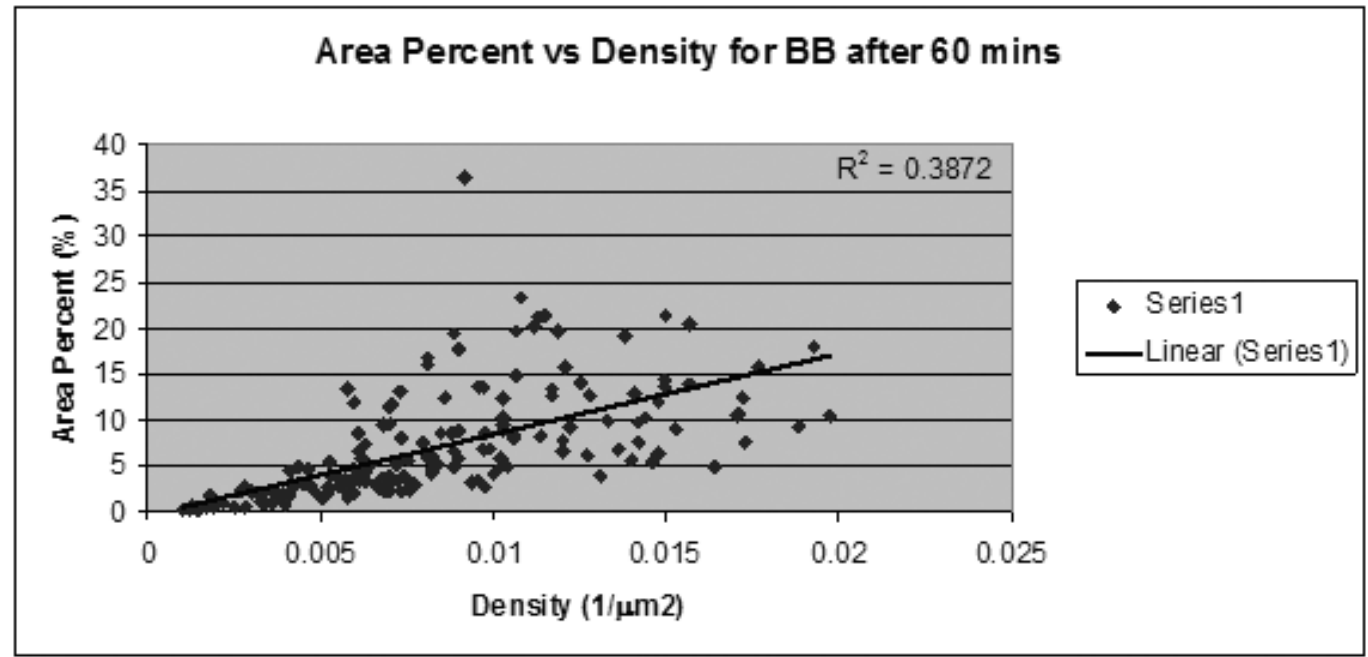

Figure 11: Area Percent vs. Density of wear for BB after 60 minutes.

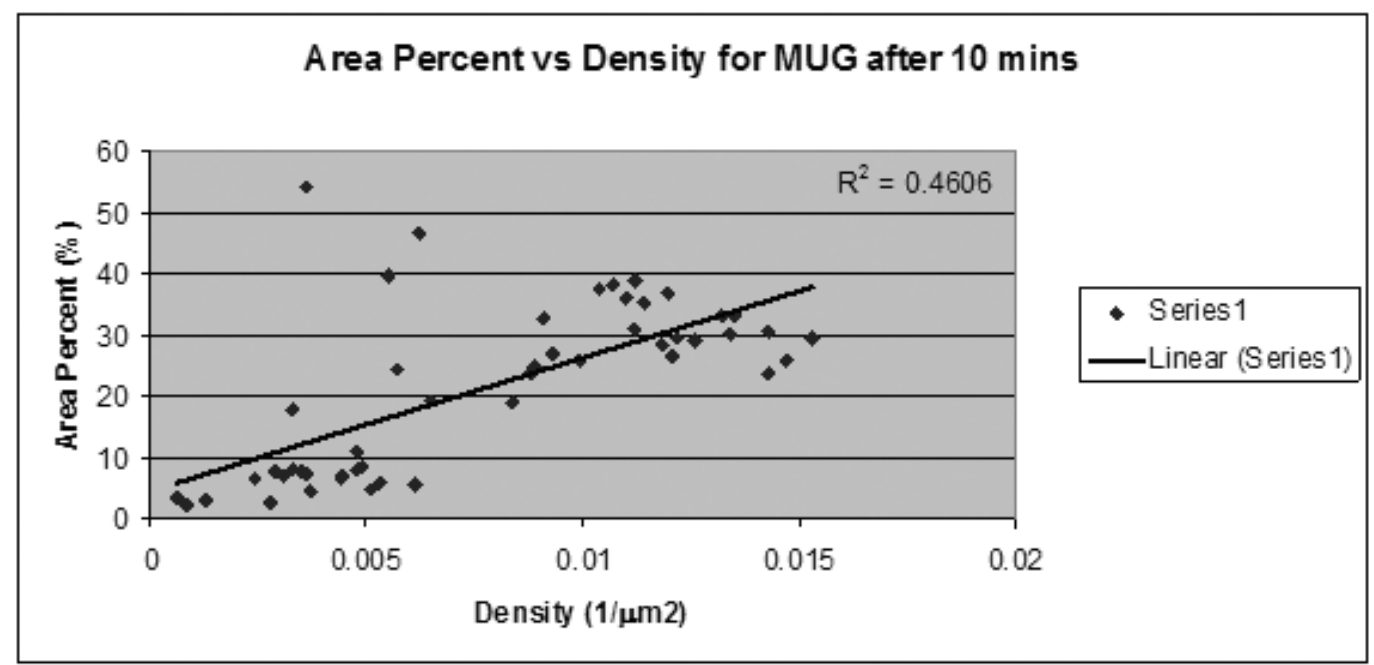

Figure 12: Area Percent vs. Density of wear for MUG after 10 minutes.

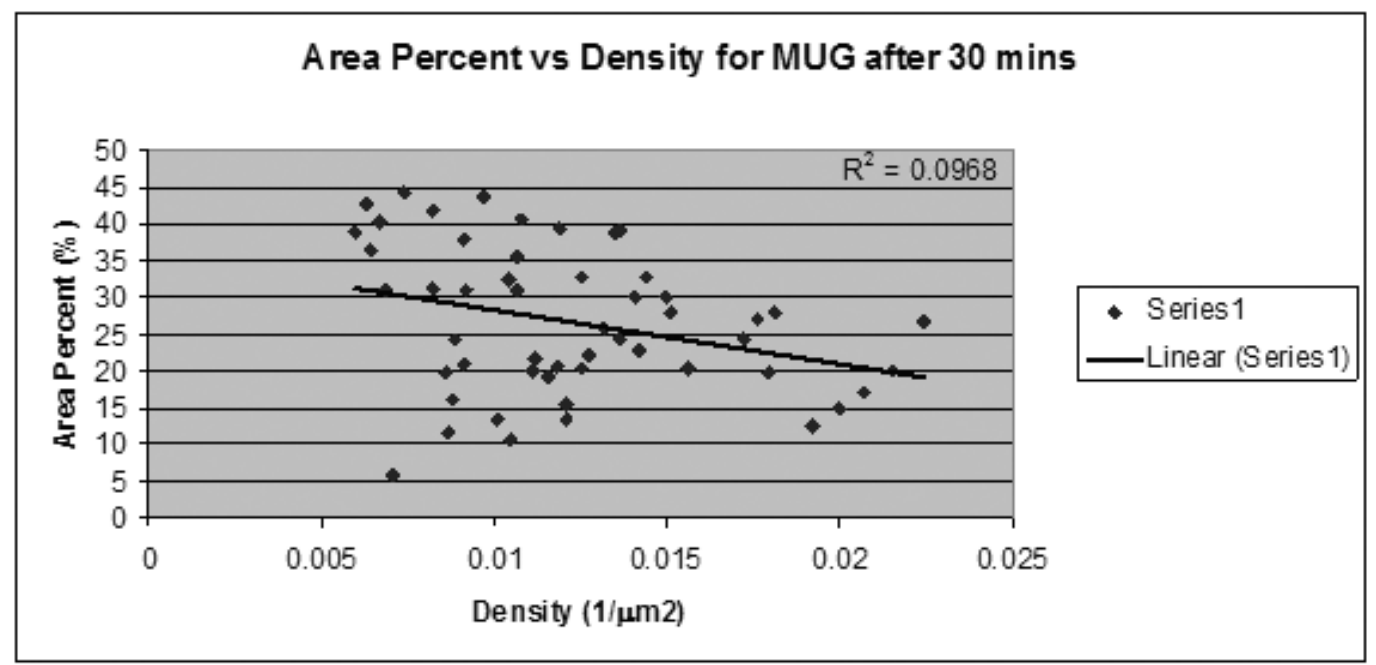

Figure 13: Area Percent vs. Density of wear for MUG after 30 minutes. 


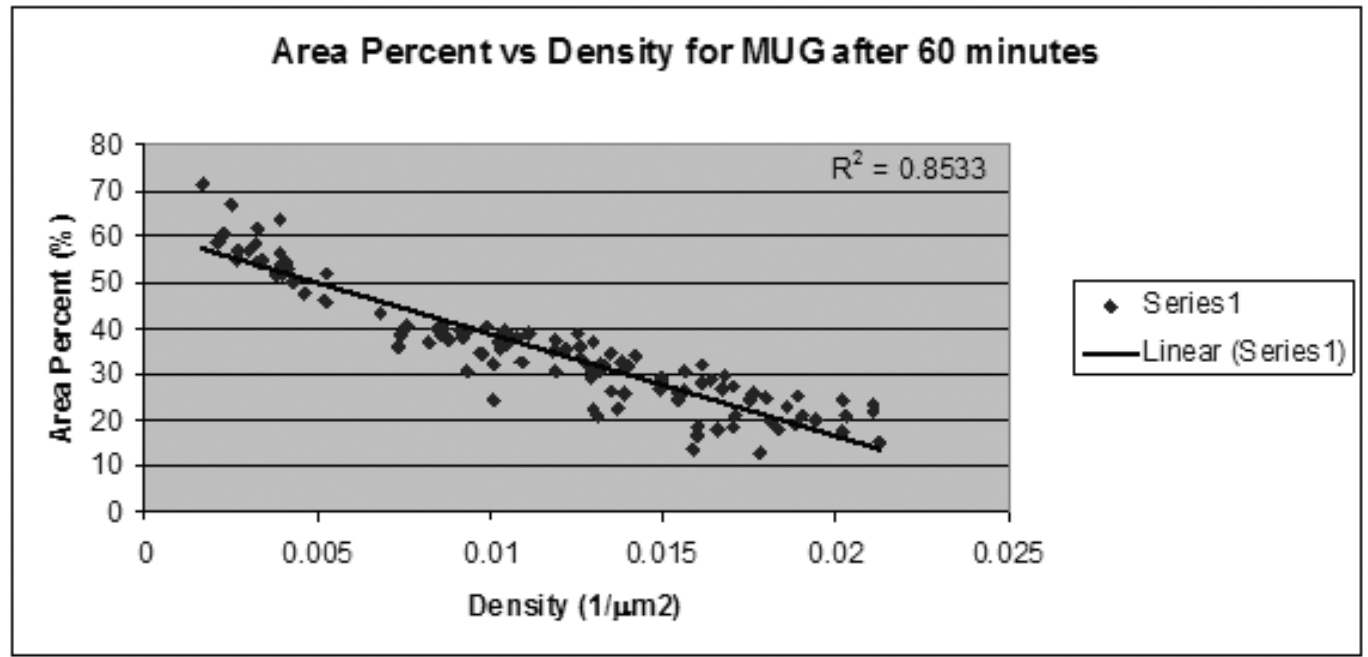

Figure 14: Area Percent vs. Density of wear for MUG after 60 minutes.

The much higher $\mathrm{R}^{2}$ for MUG after 60 minutes suggests the possibility that the combination of relatively low surface hardness and roughness (Lerner et al, 2007) may allow for a more rapid progression of wear into lower micro-topographic elevations or valleys resulting in a shift from initially more variable patterns of wear formation towards a more uniform pattern of wear propagation. Overall, the data presented here suggest that the more wear is restricted to micro-topographic peaks the more positive the correlation between area percent and density. The more wear spreads into micro-topographic valleys the more negative the correlation becomes between area percent and density.

Comparing these results to those from the previous study, $\mathrm{R}^{2}$ values for $\mathrm{YSW}$ (after 10 mins $\mathrm{R}^{2}=0.5326$, after 30 mins $\mathrm{R}^{2}=0.2244$, and after 60 mins $\mathrm{R}^{2}=0.0380$ ) exhibited the greatest variability of all four raw materials, while those for SJF (after 30 mins $R^{2}=0.8286$, and after 60 mins $\mathrm{R}^{2}=0.7313$ ) were among both the highest and most consistent among all four materials (Lerner, in press). It should be noted that SJF Tool 5 was the only flake scraper made from this material to exhibit any visible wear after 10 minutes of use (Lerner, in press), and as such was excluded from any assessment of intra-raw material variability in use-wear formation. BB exhibited fairly consistent values through all three stages of the experiment, yet they were not among the highest and MUG exhibited considerable variability but was not as far ranging as YSW. This demonstrates quantitatively the intermediate nature of BB and MUG relative to YSW and SJF within the spectrum of raw material variability described above. More generally, the collective results of the two studies show that surface hardness and surface roughness can come together in a myriad of ways to dictate a range of patterns for use-wear accrual, both within and between recognized raw material types.

Average intensity, the third variable recorded, actually presents a viable solution to a long-standing problem in use-wear research as it offers a reliable means of quantifying usewear brightness or reflectivity (Figures 15 and 16). In the case of scraping dry hide this variable measures specifically the dullness or 'matte' appearance typically associated with dry hide wear (e.g. Keeley, 1980; Vaughan, 1985; Kimball et al. 1995). The current data show an overall decrease in mean values for both BB and MUG by the end of the experiment. BB exhibited a progressive decrease through the first two stages followed by a very slight increase after the final stage of the experiment. MUG exhibited both a progressive decrease in and consistently higher values than BB.

The previous study found that the range of values for YSW (16.50 after 10 minutes, 10.55 after 30 minutes, and 8.21 after 60 minutes) were quite a bit more variable than those for SJF (6.79 after 30 minutes and 5.57 after 60 minutes) (Lerner in press). All four materials 
exhibited overall decreases in the range of average intensity values over the full course of experimentation. With the exception of BB after 10 minutes, YSW was characterized by the widest ranges of values of all four raw materials. MUG, on the other hand, was the only material to exhibit an increase in the range of values, in this isolated instance between the first and second stages of the latest experiment. SJF was characterized by the least amount of change in the range of its average intensity values.

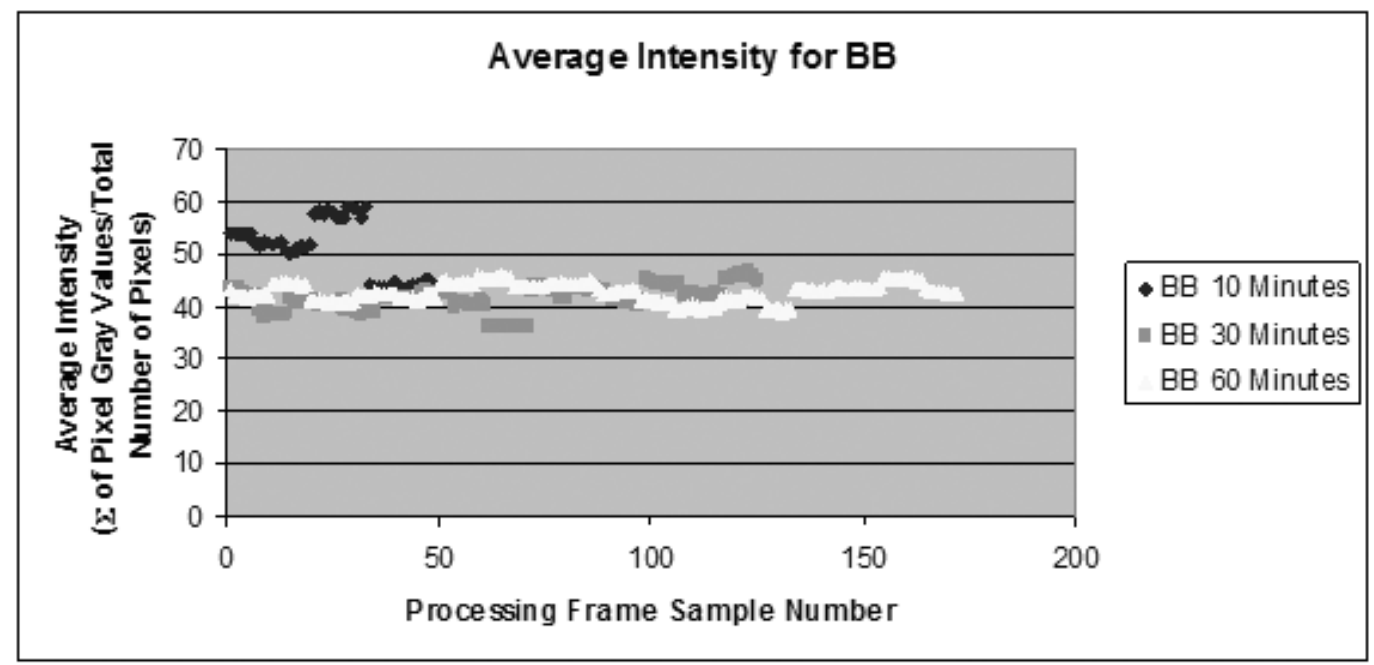

Figure 15: Average Intensity of wear for BB after each stage of the experiment.

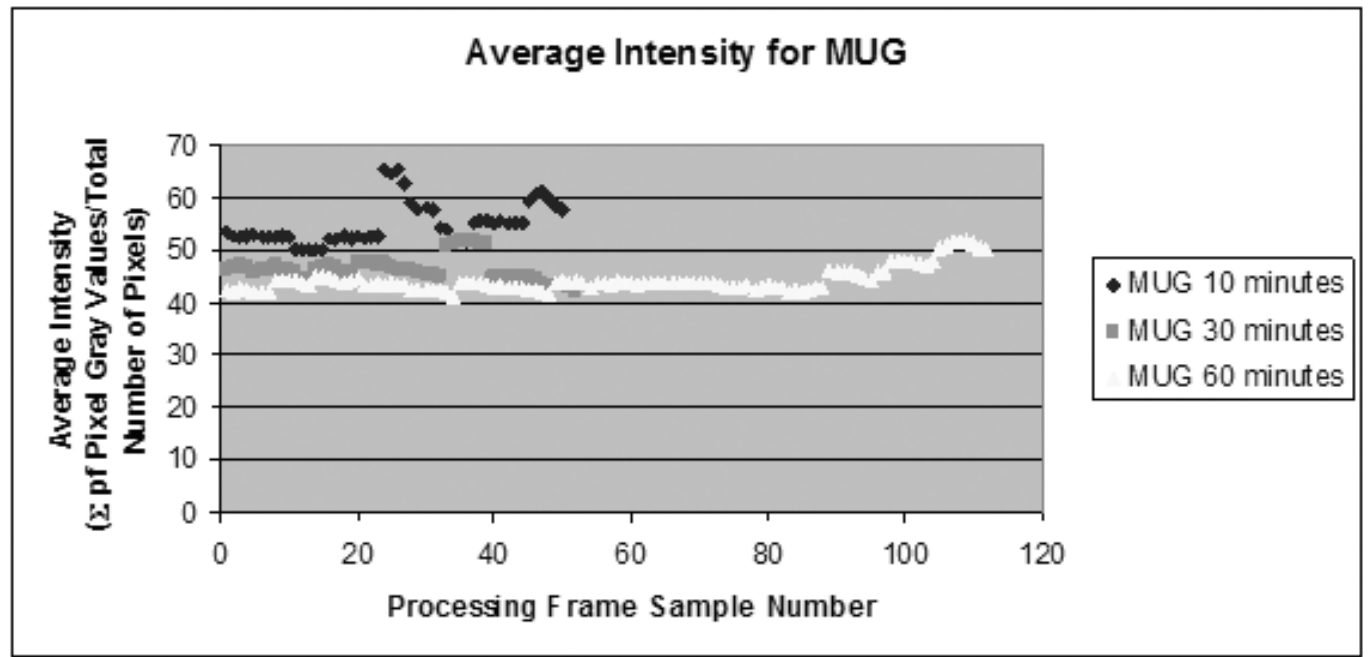

Figure 16: Average Intensity of wear for MUG after each stage of the experiment.

YSW had the highest mean average intensity values among all four raw materials $(56.22$ to 50.20) (Lerner, in press), while MUG exhibited the most pronounced decrease in mean average intensity (54.99 after 10 minutes, 46.43 after 30 minutes, and 44.24 after 60 minutes). $\mathrm{BB}$ was the only material to exhibit an increase in mean average intensity even though it was a very minor one (from 41.47 after 30 minutes to 42.74 after 60 minutes), while SJF exhibited the least amount of change in mean average intensity (47.90 after to 44.58) (Lerner, in press). Overall, the average intensity data reflect a clear yet differential dulling of polish on each raw material, as well as some differences among each set of scrapers made from each type of tool stone.

The natural heterogeneity of all lithic materials makes the use-wear analyst's job a difficult one. A more detailed appreciation of how use-related wear actually forms on and 
spreads across a given tool surface, in particular the role raw material variability plays in this process, is key to unlocking the behavioural and ultimately cultural significance of these often ambiguous traces. The present study, and the initiative as a whole, is geared towards identifying important elements of wear development and contributing to the establishment of working guidelines for the interpretation of microscopic use-wear evidence.

The general consistency of the broader patterns of wear accrual offers use-wear analysts some assurance as to the distinctiveness of use-wear patterns between different lithic raw materials, but the inherent variability within a given raw material type clearly indicates that we need to proceed cautiously when it comes to generating behavioural inferences based on these traces. Despite the complex nature of use-wear, this study and the larger initiative have further clarified both some of the variables and dynamics involved in its generation. This kind of clarification can only enhance our ability to make functional inferences about prehistoric lithic technologies and the adaptive behavior they represent.

These traces, like archaeological records themselves, are fragmentary and incomplete. This reality demands that we continue to develop the means to maximize the amount of information we can glean from these traces. We can never generate definitive interpretations about past lifeways but we can provide the methodological underpinnings to ensure reliable and informative results that can shed greater light on the prehistoric past and the people that inhabited it.

These methods should also be efficient in their application. They should be amenable to assessing large numbers of specimens in relatively short periods of time, as well as be costeffective to implement. They should also be accessible to as large a number of use-wear practitioners as possible to promote both greater standardization and comparability of results across the discipline. The Clemex image analysis program is relatively inexpensive and fairly straightforward to use. Although the technology is becoming relatively less expensive and somewhat more available, not everyone can gain access to an SEM or the financial resources to use one. The Clemex method's demonstrated compatibility with OLM suggests that Clemex image analysis can be an efficient and effective way of systematically and objectively collecting larger volumes of data in a reasonable amount of time and at a supportable cost.

\section{Conclusions}

The initial installments of what will be a long-term initiative researching the role of lithic raw material variability in patterns of use-wear formation have demonstrated that there are notable differences in how different raw materials respond to the scraping of dry ungulate hide. While this is hardly a surprising result, these studies have shown that such differences can be reliably measured. This opens the door to the possibility of using the collected data as a basis for assessing intensity of tool use in the archaeological record.

Developing this analytical ability is, and will continue to be, a long and painstaking process, involving the testing of a wider range of raw materials and the experimental performance of a greater array of subsistence-related activities. However, it is a very necessary process if we want to move past more than or less than assertions and begin offering legitimate estimates of how much more or how much less individual tools were used compared to each other. This will then pave the way for developing the means to evaluate changes in tool using behaviour and shifts in the importance of specific socio-economic activities through time and across the prehistoric landscape. This kind of information could provide a much needed corroborative line of evidence regarding the evolution of prehistoric economies, particularly when it comes to the often complex transitions from smaller-scale hunting and gathering to full-scale agriculture. 
The broader goals of the larger initiative are indeed challenging and will require considerable time and effort to be achieved. However, it is believed that all that hard work has significant potential to yield significant methodological and interpretive dividends that will in time contribute towards our collective effort to resolve a number of issues that are, at present, still up for considerable debate. The approach described here can and should be part of a larger, more holistic methodological paradigm that incorporates multiple analytical techniques that generate several lines of evidence. Such an inclusive perspective would provide broader behavioural contexts for more fully evaluating the kind of quantitative data we are working to collect. This is the most promising way to assess the full significance of use-wear evidence as both behavioural and cultural phenomena.

The results presented here and in previous installments may give the immediate impression of muddying the interpretive waters, and in a sense they do. However, shoring up the methodological foundation for generating reliable interpretations of often ambiguous microscopic evidence necessitates a stirring-up of the status quo to see where exactly all the analytical dust will settle and what bigger picture it may ultimately reveal.

\section{Acknowledgements}

I would also like to thank Dr. Jacques Chabot and the L'Équipe Archéometrie at the Laboratoires d' Archéologie, a part of the Centre Interuniversitaire d'Études sur les Lettres, les Arts et les Traditions (CELAT) at Université Laval, Quebéc (Quebéc), Canada for supporting this research. My thanks also go the reviewers for their many useful comments and suggestions that made this an even better paper.

\section{References}

Anderson, P.C. 1980, A testimony of prehistoric tasks: diagnostic residues on stone tool working edges. World Archaeology, 12(2): 181-194. doi: $\underline{10.1080 / 00438243.1980 .9979791}$

Alilou, Mehdi and Kovalev, Vassili 2013, Automatic Object Detection and Segmentation of the Histocytology Images Using Reshapable Agents. Image Analysis and Stereology, 32: 89-99. DOI: 10.5566/ias.v32.p89-99

Barceló Álvarez, J. A., Pijoan-Lòpezm J., Toselli, A., and Vila I Mitjà, Assumpció 2008, Kinematics in use-wear traces: an attempt of characterization through image Digitalization. In: 'Prehistoric Technology' 40 Years Later: Functional Studies and the Russian Legacy, (Longo, L. and Skakun, N., Eds.), BAR International Series Vol. 1783, Archaeopress, Oxford, p. 63-71.

Cootes T. 2000, Model-based Methods in Analysis of Biomedical Images. In: Image Processing and Analysis: a Practical Approach, (Baldock, R. and Graham, J., Eds.), Oxford University Press, Oxford, p. 223-248.

Derndarsky M. and Ocklind G. 2001, Some Preliminary Observations on Subsurface Damage on Experimental and Archaeological Quartz Tools using CLSM and Dye. Journal of Archaeological Science, 28(11): 1149-1158. doi:10.1006/jasc.2000.064

Dumont J.V. 1982, The Quantification of Microwear Traces: A New Use for Interferometry. World Archaeology 14(2): 206-217. Stable URL: http://www.jstor.org/stable/124276 
Evans A.A. and Donahue R.E. 2008, Laser scanning confocal microscopy: a potential technique for the study of lithic microwear. Journal of Archaeological Science, 35(8): 2223-2230. doi:10.1016/j.jas.2008.02.006

Evans, A.A., Macdonald, D. 2011, Using metrology in early prehistoric stone tool research: further work and a brief instrument comparison. Scanning 33(5): 294-303. doi:10.1002/sca.20272

Goodman, Mary Ellen 1944, Physical Properties of Stone Tool Materials. American Antiquity 9(4): 415-433. Stable URL: http://www.jstor.org/stable/275093

González Urquijo, J. E. and Ibáñez Estévez, J. J. 2003, The quantification of use-wear polish using image analysis: First results. Journal of Archaeological Science 30(4): 481-489. doi: $10.1006 /$ jasc. 2002.0855

Grace R. 1989, Interpreting the function of Stone Tools: The Quantification and Computerization of Microwear Analysis, BAR International Series, Vol. 474, Archaeopress, Oxford, 255 p.

Grace R. 1990, The limitations and applications of use-wear analysis. In: The Interpretive Possibilities of Microwear Analysis, (Graslund, B., Knutsson, H., Knutsson, K., Taffinder, J., Eds.) Societas Archaeologica Upsaliensis, Uppsala, Vol. 14, Sweden, p. 914.

Grace R., Graham I.D.G. and Newcomer M.H. 1985, The Quantification of Microwear Polishes. World Archaeology 17(1): 112-120. Stable URL: http://www.jstor.org/stable/124679

Grace R., Graham I.D.G. and Newcomer M.H. 1987 The Mathematical Characterization of Wear Traces on Prehistoric Flint Tools. In: The Human Uses of Flint and Chert: Papers from the Fourth International Flint Symposium, (Sieveking, G. and Newcomer, M. H.) p. 63-69.

Graham J. 2000, Pattern Recognition: Classification of Chromosomes. In: Image Processing and Analysis: a Practical Approach, (Baldock, R. and Graham, J., Eds.), Oxford University Press, Oxford, p. 111-152.

Gramfort, A., Poupon, C., and Descoteaux, M. 2014, Denoising and Fast Diffusion Imaging with Physically Constrained Sparse Dictionary Learning. Medical Image Analysis, 18(1): 36-39. doi:10.1016/j.media.2013.08.006

Greiser, Sally T. and Payson D. Sheets 1979, Materials as a Functional Variable in UseWear Studies.. In: Lithic Use Wear Analysis, (Hayden, B., Ed.), Studies in Archaeology Series, Academic Press, New York, p. 289-296.

Kimball, L.R., Kimball, J.R. and Allen, P.E. 1995, Microwear polishes as viewed through the atomic force microscope. Lithic Technology, 20(1): 6-28. Stable URL: http://www.jstor.org/stable/23273157

Ibáñez Estévez, J.J., González Urquijo, J.E., Peña-Chocarro, L., Zapata, L., Beugnier, V. 1999, Harvesting without sickles: Neolithic examples from humid mountain areas. In: Ethno-archaeology and its transfers, (Beyries, S. and Pétrequin, P.), BAR International Series Vol. 983, Archaeopress, Oxford, p. 23-36.

Laferty D. 2000, Image Analysis: Historical Perspective. In: Practical Guide to Image Analysis, ASM International: The Materials Information Society, American Society for Metals International, Materials Park, Ohio, p. 1-14. 
Lerner, H. 2007a, Digital Image Analysis and Use-wear Accrual as a Function of Raw Material: An Example from Northwestern New Mexico. Lithic Technology 32 (1): 5167. Stable URL: http://www.jstor.org/stable/23273643

Lerner, H. 2007b, Lithic Raw Material Variability and the Reduction of Short-term Use Implements: An Example from Northwestern New Mexico, BAR International Series 1688, Oxford, $170 \mathrm{p}$.

Lerner, H. 2009, Lithic Raw Material Variability and Use-wear Accrual on Short-term Use Implements: An Example from Northwestern New Mexico. In: Non-flint Raw Material Use in Prehistory: Old Prejudices and New Directions, (Sternke, F., Costa, L. J., and Eigeland, L., Eds.) Proceedings of the 15th Congress of the U.I.S.P.P. Archaeopress, Oxford, p. 81-91.

Lerner, H. (in press) Intra-Raw Material Variability and Use-wear Formation: An Experimental Examination of a Fossiliferous Chert (SJF) and a Silicified Wood (YSW) from NW New Mexico using the Clemex Vision Processing Frame. Journal of Archaeological Science. doi:10.1016/j.jas.2013.10.030

Lerner, H., Du X., Costopoulos A., Ostoja-Starzewski M. 2007, Lithic raw material physical properties and use-wear accrual. Journal of Archaeological Science 34(5): 711-722. doi:10.1016/i.jas.2006.07.009

Lerner, H., Dytchkowskyi, D., and Nielsen, C. 2010, Raw material variability, use-wear accrual rates and addressing the ambiguity of some use-wear traces: an example from northwestern New Mexico. Rivista di Scienze Preistoriche 15: 309-329.

Mansur M.E. 1997, Functional analysis of polished stone-tools: some considerations about the nature of polishing. In: Siliceous rocks and culture, (Bustillo, M. A. and Ramos Millán, A., Eds.). University de Granada, p. 465-486.

Mansur M.E. 1999, Análisis funcional de instrumental lítico: problemas de formación y deformación de rastros de uso. In: Actas del XII Congreso Nacional de Arqueología Argentina, Universidad Nacional de La Plata, p. 355-366.

Mansur-Franchomme, M. E. 1983a, Traces d'utilisation et technologie lithique: exemples de la Patagonie. PhD. Thesis, Bordeaux I Univ., Bordeaux. 516 p.

Mansur-Franchomme, M. E. 1983b, Scanning electron microscopy of dry hide working tools: the role of abrasives and humidity in microwear polish formation. . Journal of Archaeological Science 10(3): 223-230. doi:10.1016/0305-4403(83)90005-5

Mansur-Franchomme, M. E. 1986, Microscopie du matériel lithique préhistorique. Traces d'utilisation, altérations naturelles, accidentelles et technologiques. Cahiers du Quaternaire n ${ }^{\circ}$ 9, Editions du CNRS. Bordeaux. 286 p.

McDevitt, K. B. 1994, Results of Replicative Hide-Working Experiments: The Roles of Raw Material, Hide Condition, and Use-Wear Patterns in the Determination of Rhyolite Endscraper Function. Lithic Technology 19(2): 93-97. Stable URL: http://www.jstor.org/stable/23272946

Moreaud, M., Revel, R., Jeulin, D., and Morard, V. 2009, Size of Boehmite Nanoparticles by TEM Images Analysis. Image Analysis and Stereology, 28: 187-193.

Parr, G. and W. Polzleitner 2001, Fundamentals. In: Digital Image Analysis: Selected Techniques and Applications, edited by Walter G. Kropatsch and Horst Bischof, Springer, New York, p. 373-392. 
Rottensteiner, F. 2001, Precise Photogrammetric Measurement. In: Digital Image Analysis: Selected Techniques and Applications, edited by Walter G. Kropatsch and Horst Bischof, Springer, New York, p. 411-438.

Semenov, S.A. 1964, Prehistoric Technology, Translated by M.W. Thompson, Cory, Adams and Mackay, London, $211 \mathrm{p}$.

Stemp, W.J., Childs, B.E., Vionnet, S. 2010, Laser profilometry and length-scale analysis of stone tools: second series experiment results, Scanning 32(4): 233-243. doi: $10.1002 /$ sca. 20200

Stemp, W.J., Stemp, M. 2001, UBM laser profilometry and lithic use-wear analysis: a variable length scale investigation of surface topography. Journal of Archaeological Science 28(1): 81-88. doi:10.1006/jasc.2000.054

Stemp, W.J., Stemp, M. 2003, Documenting stages of polish development on experimental stone tools: surface characterization by fractal geometry using UBM laser profilometry. Journal of Archaeological Science 30(3): 287-296. doi:10.1006/jasc.2002.0837

Xu, J., Janowczyk, A., Chandran, S., and Madabhushi, A. 2011, A High-Throughput Active Contour Scheme for Segmentation of Histopathological Imagery. Medical Image Analysis, 15(6): 851-862. doi:10.1016/j.media.2011.04.00

Yoo, T. S., and Metaxas, D. N. 2005, Open Science - Combining Open Data and Open Source Software: Medical Image Analysis with the Insight Toolkit. Medical Image Analysis, 9(6): 503-506. doi:10.1016/j.media.2005.04.008 